\title{
Effects of Human Alpha-Synuclein A53T-A30P Mutations on SVZ and Local Olfactory Bulb Cell Proliferation in a Transgenic Rat Model of Parkinson Disease
}

\author{
Faustine Lelan, ${ }^{1,2,3,4}$ Cécile Boyer, ${ }^{1,2,3,4}$ Reynald Thinard, ${ }^{1,2,4}$ Séverine Rémy, ${ }^{1,2,4}$ \\ Claire Usal, ${ }^{1,2,4}$ Laurent Tesson, ${ }^{1,2,4}$ Ignacio Anegon, 1, 2, 3, 4 Isabelle Neveu, , 2, 3, 4 \\ Philippe Damier, , 2, 4, 5 Philippe Naveilhan, ${ }^{1,2,3,4}$ and Laurent Lescaudron ${ }^{1,2,3,4,6}$ \\ ${ }^{1}$ INSERM U 643, CHU Hôtel Dieu, 30 boulevard Jean Monnet, 44093 Nantes cedex 1, France \\ ${ }^{2}$ Institut de Transplantation, Urologie Néphrologie (ITUN), 44093 Nantes cedex 1, France \\ ${ }^{3}$ UFR de Médecine, Université de Nantes, 44093 Nantes cedex 1, France \\ ${ }^{4}$ CHU de Nantes, 44093 Nantes cedex 1, France \\ ${ }^{5} \mathrm{CHU}$ de Nantes, CIC 04, Pôle Neurosciences, Nantes, France \\ ${ }^{6}$ Service de Physiologie Animale et Humaine, UFR des Sciences et des Techniques, Université de Nantes, 44322 Nantes cedex 3 , France
}

Correspondence should be addressed to Laurent Lescaudron, laurent.lescaudron@univ-nantes.fr

Received 13 October 2010; Revised 21 February 2011; Accepted 19 April 2011

Academic Editor: David S. Park

Copyright (C) 2011 Faustine Lelan et al. This is an open access article distributed under the Creative Commons Attribution License, which permits unrestricted use, distribution, and reproduction in any medium, provided the original work is properly cited.

\begin{abstract}
A transgenic Sprague Dawley rat bearing the A30P and A53T $\alpha$-synuclein ( $\alpha$-syn) human mutations under the control of the tyrosine hydroxylase promoter was generated in order to get a better understanding of the role of the human $\alpha$-syn mutations on the neuropathological events involved in the progression of the Parkinson's disease (PD). This rat displayed olfactory deficits in the absence of motor impairments as observed in most early PD cases. In order to investigate the role of the mutated $\alpha$-syn on cell proliferation, we focused on the subventricular zone (SVZ) and the olfactory bulbs (OB) as a change of the proliferation could affect OB function. The effect on OB dopaminergic innervation was investigated. The human $\alpha$-syn co-localized in TH-positive OB neurons. No human $\alpha$-syn was visualized in the SVZ. A significant increase in resident cell proliferation in the glomerular but not in the granular layers of the OB and in the SVZ was observed. TH innervation was significantly increased within the glomerular layer without an increase in the size of the glomeruli. Our rat could be a good model to investigate the role of human mutated $\alpha$-syn on the development of olfactory deficits.
\end{abstract}

\section{Introduction}

Parkinson's disease (PD) is the second most common neurodegenerative disorder. It is mainly characterized by a progressive and massive loss of dopaminergic (DA) neurons in the substantia nigra pars compacta (SNpc), which leads to several clinical motor symptoms such as akinesia, rigidity and resting tremor $[1,2]$. The molecular pathways leading to these concomitant clinical alterations remain obscure, but it is believed that it may result from environmental factors, genetic causes, or a combination of the two [3]. The first gene discovered involved in the disease was the $\alpha$-synuclein ( $\alpha$-syn) gene. Mutations of this gene are responsible for autosomal dominants forms of $\mathrm{PD}[4,5]$. Indeed, three missense mutations in the $\alpha$-syn gene have been found in patient families: A30P, A53T, and E46K [4, 6, 7]. Alpha-syn has an increased propensity to aggregate due to its hydrophobic nonamyloid- $\beta$ component domain and the presence of fibrillar $\alpha$-syn as a major structural component of Lewy body, a pathological hallmark of Parkinson's disease and suggests a role of aggregated $\alpha$-syn in disease pathogenesis [8]. Alpha-syn is a natively unfolded presynaptic protein which has a role in compartmentalization, storage, and recycling of neurotransmitters. It is involved in physiological regulation of certain enzymes such as tyrosine hydroxylase ( $\mathrm{TH})$ and increases the number of dopamine transporter molecules [1]. On the contrary, it is implicated in downregulation of the activity of the vesicular monoamine transporter-2 (VMAT-2). 
In order to understand better the effects of the $\alpha$-syn mutation on the neuropathology and progression of $\mathrm{PD}$, transgenic mouse models were generated. However, mostly due to the choice of the promoter, the expression of mutated human $\alpha$-syn was often located in non-DA brain structures [9-11]. In addition, when $\alpha$-syn aggregates were visualized in the SNpc, no significant DA neuronal cell loss was noticed although motor deficits were observed [1, 11-15].

These transgenic mice models were more suitable to study whole brain $\alpha$-synucleinopathy than to investigate the precise role of $\alpha$-syn on DA structures, therefore a search for better animal models of PD continued. Thus, about a decade ago, Lo Bianco et al. [16] and Yamada et al. [17] showed that lentiviral vectors expressing wild-type or mutant human A30P and A53T forms of $\alpha$-syn injected into the rat $\mathrm{SNpc}$ induced, in contrast to transgenic mouse models, a selective loss of nigral DA neurons, DA denervation of the striatum as well as significant motor impairments [18]. These studies demonstrated that the rat has specific sensitivity of SNpc DA neurons to human $\alpha$-syn, but this new model of PD lacked the progressive nature of the disease observed in humans. In the light of these previous studies, we generated a transgenic rat bearing both the A30P and A53T $\alpha$-syn human mutations $[19,20]$ in order to get a better understanding of the human $\alpha$-syn role on the neuropathological events involved in the progression of the disease. In the mouse, the A30P mutant form [21] or the A53T mutant form [22] of $\alpha$ syn showed a decrease in the neurogenesis in the glomerular and granular layers of the olfactory bulbs (OBs). This is the reason why the present study focused on the subventricular zone (SVZ) proliferation and the OB local proliferation. Alteration of SVZ and local OB proliferation could also affect OB function, as most of the time, hyposmia precede clinical motor symptoms in Parkinson's disease [23].

In the adult brain, neural stem cells from the anterior portion of the SVZ give rise to neuroblasts that migrate along the rostral migratory stream to the OB [24]. Within the granule cell and glomerular layers of the $\mathrm{OB}$, a persistent proliferative activity of progenitor cells is observed [24]. Then, the cells differentiate into functional granular GABAergic and periglomerular DA olfactory interneurons.

To summarize, we investigated the effects of the human double A30P and A53T $\alpha$-syn mutations on SVZ and local $\mathrm{OB}$ proliferation with an additional focus on $\mathrm{OB}$ DA innervations [25].

\section{Materials and Methods}

2.1. Generation of the Transgenic Human A53T and A30P $\alpha$-synuclein Rat. The transgene construct pUTHTV $\mathrm{hm}^{2} \alpha$ SYN (Figure 1) was created by Richfield et al. [14] and kindly given by H.J Federoff (University of Rochester, New York). Briefly, the transgene was composed of the A30P and A53T double mutated form of human $\alpha$-syn under the control of the rat tyrosine hydroxylase $(\mathrm{TH})$ promoter. The current method of gene transfer, microinjection, which is widely used in transgenic mouse production, was successful in obtaining transgenic rats. The microinjection of Sprague
Dawley rat ovocytes into male pronucleus were generated by the INSERM UMR643 transgenic rat common facility (Nantes, France) and by genOway company (Lyon, France). The present study was performed with one of the 3 transgenic rat lines that were generated, the MA3 transgenic rat line.

All experiments were carried out in accordance with the regulations of the University of Nantes Animal Health Committee.

\subsubsection{Analysis of the Olfaction, Modified from Lemasson et al.} [26] and Gross Motor Locomotion. After habituation, the animal was placed one time per month in the middle of an open field apparatus $(600 \times 600 \times 400 \mathrm{~mm})$ equipped with infrared beams and connected to a computer to analyze locomotion and time spent in the four quadrants of the maze for a 2-minute period (Imetronic, Pessac, France). In one corner, a filter paper $(70 \times 30 \mathrm{~mm})$ located at a height of $10 \mathrm{~cm}$, was soaked in fresh coconut milk (half diluted in distilled water; Tables du Monde, Leclerc Company France). Coconut milk is known to be a very attractive odor for the rat. In the opposite corner, the same size paper filter was soaked in distilled water, considered as a neutral odor. The time spent by the rat in both corners is recorded. The results are expressed as the ratio of time spent in the corner with the coconut milk filter paper/the time spent in the corner with the distilled water filter paper. A higher ratio (i.e., more time spent in the corner with the coconut milk filter paper) demonstrates that the animal was able to smell the odor of the coconut milk. During habituation and olfaction testing, the animals were studied for locomotor impairments by a hidden observer. Five animals were used in both groups. The day before the first olfaction testing, the rat is placed in the apparatus (without filter paper) for $30 \mathrm{~min}$. During olfaction testing, the rat is recorded to examine if there was any gross impairments in the motor pattern.

2.1.2. Lateral Stepping Test and Movement Initiation. Each animal was systematically handled on a regular basis for several days before the first assessment. Briefly, in this test evaluating the initiation of the movement, the experimenter firmly suspended the rat's hindquarters and restricted one of its forelimbs, while the rat supported its weight on the other forelimb. Then, the experimenter moved the rat along the table ( $0.9 \mathrm{~m}$ in 5 seconds) on the right limb, three times consecutively per session. Then, the rat undergoes the same test for its left paw. All the sessions (left and right) were recorded to allow the number of adjusting steps to be counted by an investigator blinded to the state of the rat (i.e., transgenic or wild type). For each session (left and right), the total score calculated was the mean of the number of adjusting steps observed in the three tests (for the right and the left paw). Then data from left and right were averaged giving one value per animal. Data are presented as mean values per group.

2.2. BrdU Injection. Groups of 5 wild-type (WT) and 4 transgenic female Sprague Dawley rats were sacrificed at 


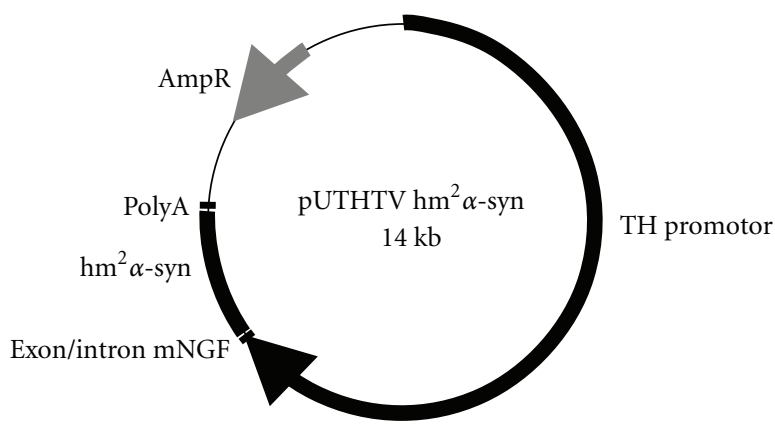

Constructed by Federoff

(a)

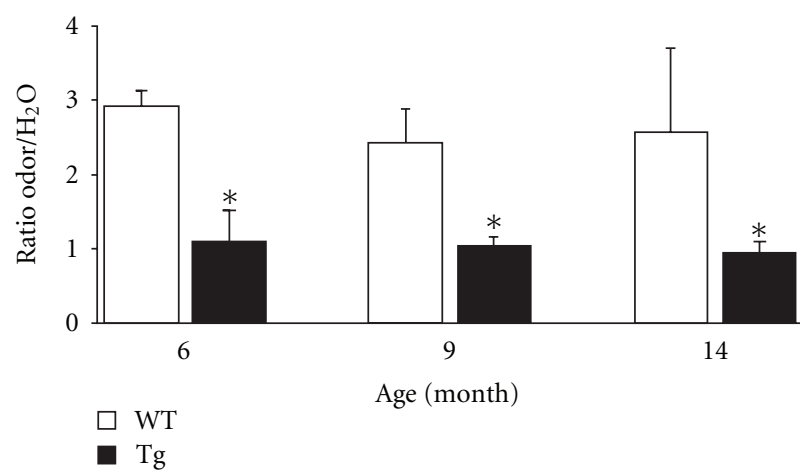

(b)

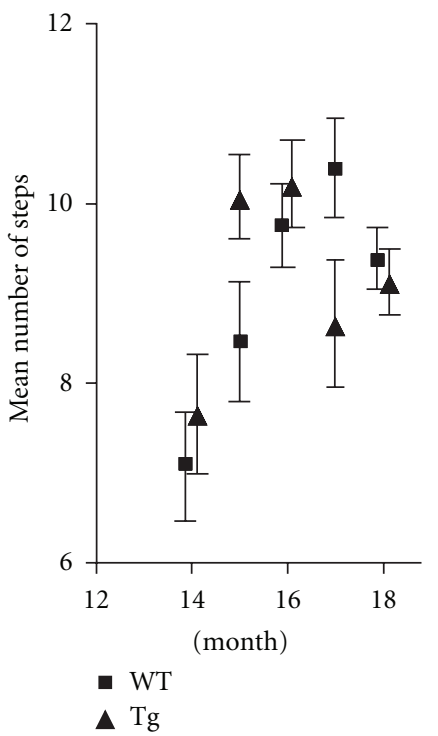

(c)

Figure 1: (a) Transgene construction. The transgene construct pUTHTV hm² $\alpha$-Syn is composed of double mutated form of human $\alpha$-syn $\left(\mathrm{hm}^{2} \alpha\right.$-SYN) with A30P and A53T mutations under the control of the 9-kb rat tyrosine hydroxylase promoter. (b) There is a significant difference in the ratio odor/H20 between the 2 groups of rats $\left({ }^{*} P<.05\right.$, with the odor being from the coconut milk) in the olfaction test. The WT rats spent more time in the corner with the coconut milk filter paper as compared to the corner with the distilled water (ratio superior to 2). Transgenic animals spent less time in the corner with the coconut milk as a ratio of 1 corresponds to the same period of time spent in both corners. No significant ratio difference was observed between 6, 9, and 14 months for both groups of animals. (c) There is no significant difference in lateral stepping performance between WT and Tg animals indicating that no motor deficits in 18-month old Tg animals.

25 months of age. At that age, transgenic rats displayed a severe olfactory deficit. In order to label proliferative cells, $\mathrm{BrdU}(100 \mathrm{mg} / \mathrm{Kg})$ was injected intraperitoneally once a day during 5 consecutive days and the animals were sacrificed 5 hours after the last injection. This protocol was aimed to detect local proliferation rather than neurogenesis as changes in local $\mathrm{OB}$ proliferation could take part in the olfactory alterations observed in our transgenic rat.

2.3. Tissue Preparation. All animals were deeply anesthetized with Rompun/Ketamine ( $1 \mathrm{~mL} / \mathrm{Kg}$ i.m. $)$ and transcardially perfused with ice-cold $4 \%$ paraformaldehyde in phosphate buffered (PB). Brains were rapidly removed, immersed in the same fixative for $24 \mathrm{~h}$ at $4^{\circ} \mathrm{C}$ and stored in $15 \%$ sucrose in PB for 48 hours and then in 30\% sucrose for an additional
24 hours. Brains were then frozen at $-40^{\circ} \mathrm{C}$ in isopentane (Prolabo, Fontenay-sous-Bois, France). Serial sixteenmicrometer-thick coronal sections through the whole brain were cut on a cryostat (Leica, CM 3050) and then collected on gelatin-coated slides.

2.4. Immunohistochemistry. The brain sections were thoroughly washed with PBS prior to immunohistochemical labeling. They were then labeled with antibodies against TH to identify catecholaminergic neurons $(1: 1000$; Pel-Freeze, Brown Deer,WI), against the human- $\alpha$-syn to characterized neurons expressing the human $\alpha$-syn (1:500; Invitrogen, Cergy Pontoise, France) and against BrdU to quantify proliferative cells $(1: 200 ; \mathrm{BD}$, USA). One section out of 6 serial sections was stained for each immunohistochemistry labeling. 
WT

TH

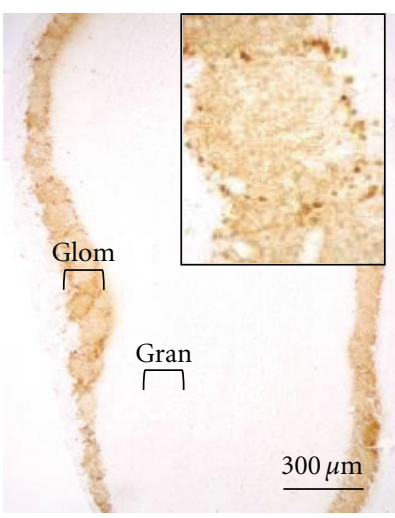

(a)

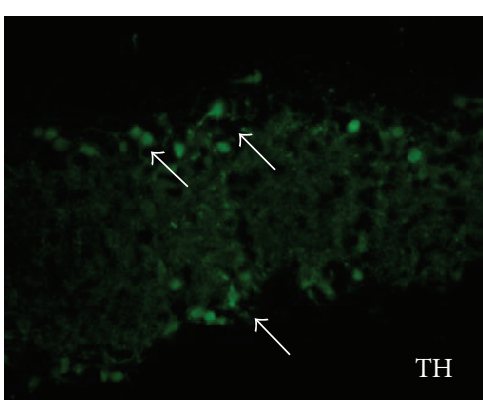

(e)

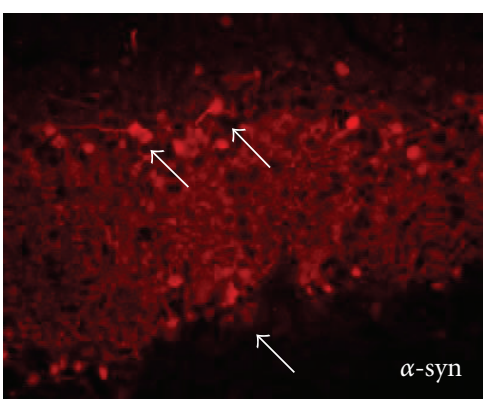

(f)

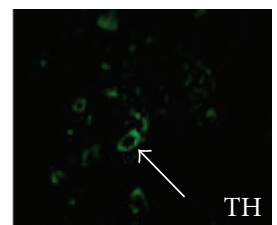

(h)

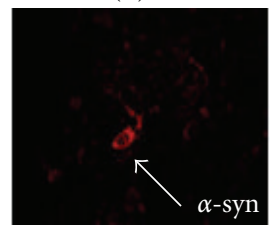

(i) $\alpha$-synuclein

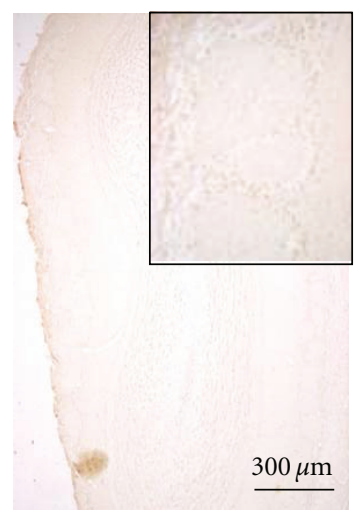

(b)
Ts

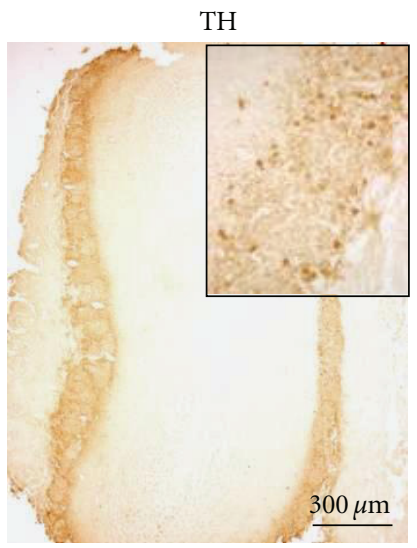

(c)

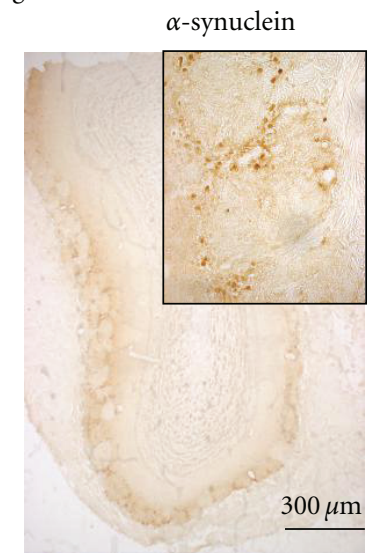

(d)

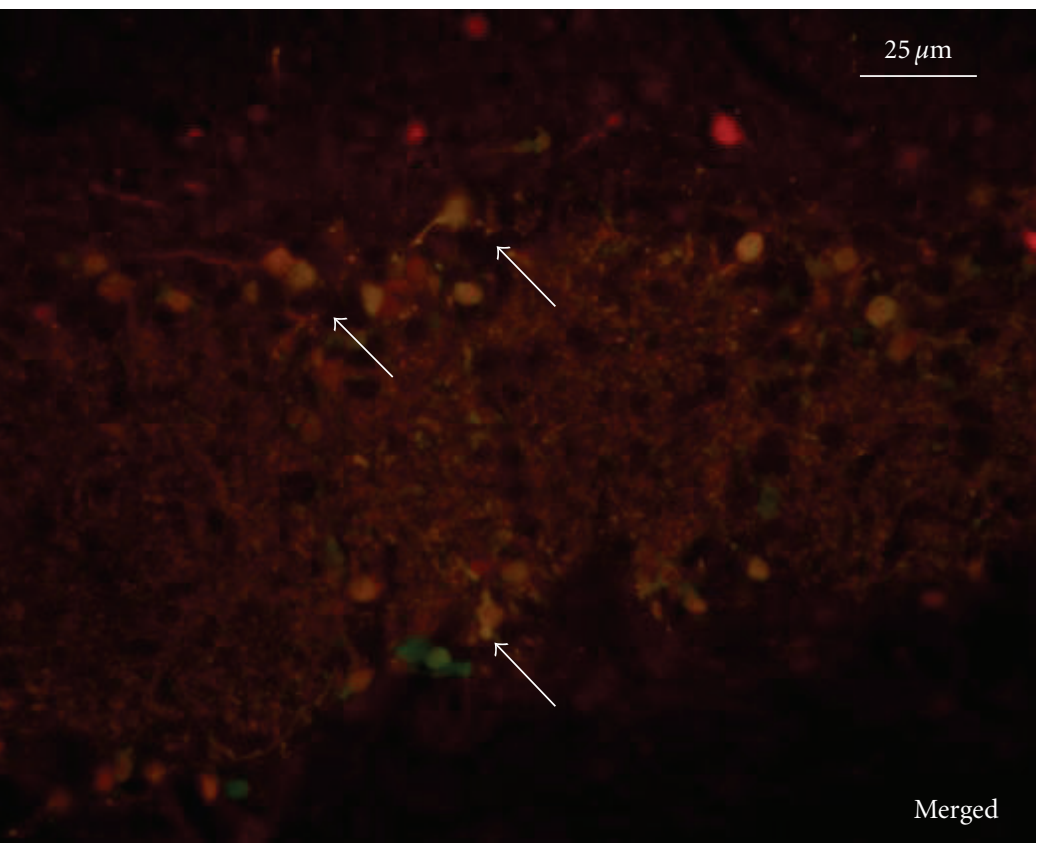

(g)

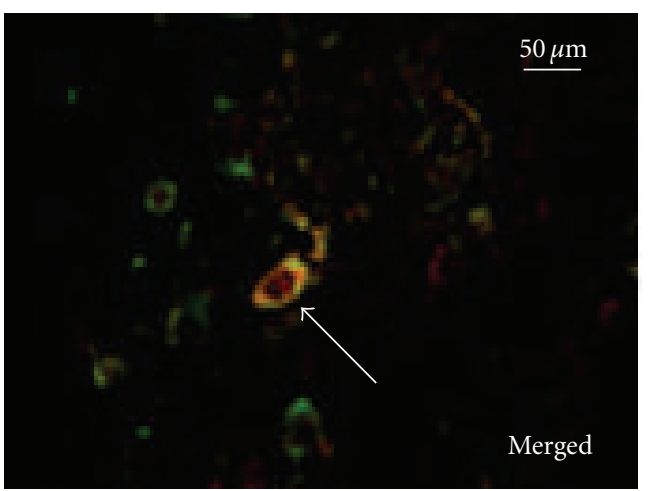

(j)

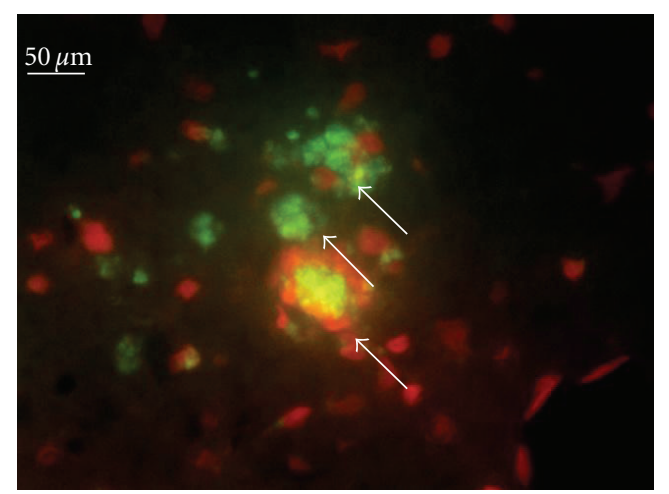

(k)

FIgURE 2: Alpha-synuclein, tyrosine hydroxylase (TH), thioflavin T, and BrdU stainings in wild-type (WT) and transgenic (Tg) rats. Overview of TH expression in wild-type (WT, a) and transgenic (Tg) olfactory bulbs (c). Alpha-syn immunostaining on a section of olfactory bulb of WT (b) and transgenic rat (d). Higher magnification of a Tg glomerular layer stained for TH in green (e), for $\alpha$-syn in red (f), and with merged stainings (g). Arrows point out some of the many neurons expressing both TH and $\alpha$-syn (stained in yellow in g). Confocal visualizations in transgenic rat of TH (h), human $\alpha$-syn (i), and merged TH and $\alpha$-syn (j). Arrows in h, i, and j point out a TH positive neuron (in green) expressing the human $\alpha$-syn (in red). (k) Visualization of protein aggregates (arrows) in a Tg glomerular layer using thioflavin $\mathrm{T}$, cell bodies are in red. 


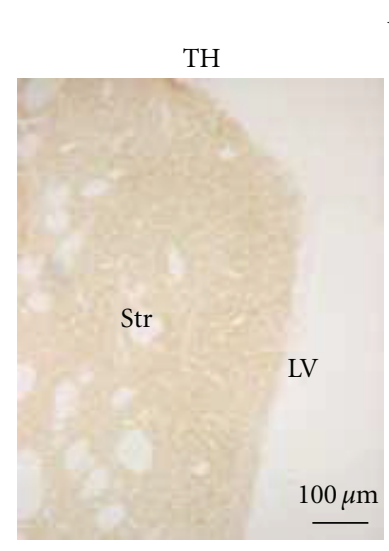

(a)

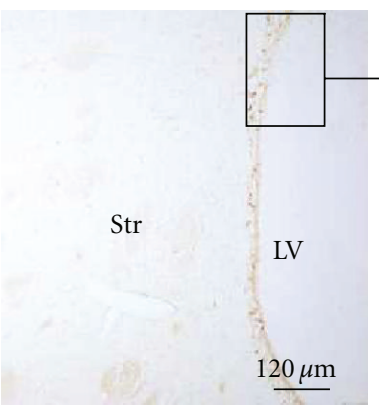

(e)

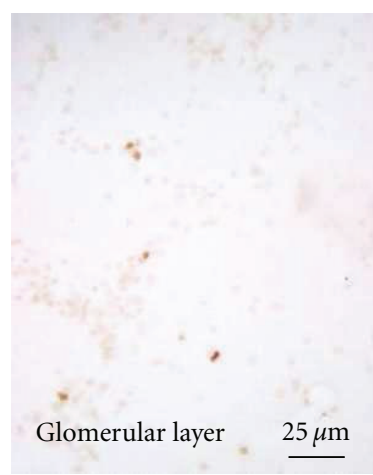

(i)
WT

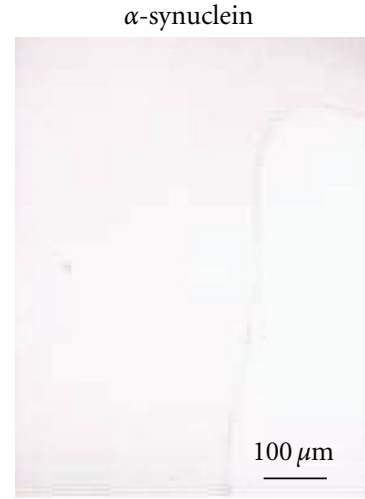

(b)

BrdU

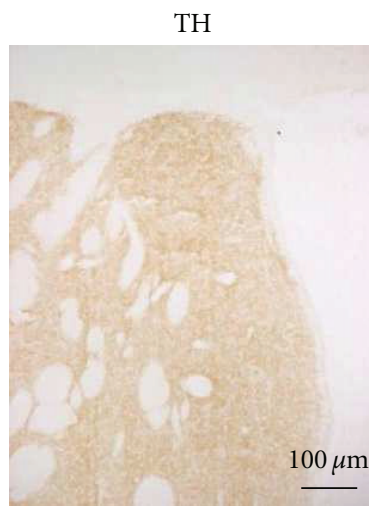

(c)

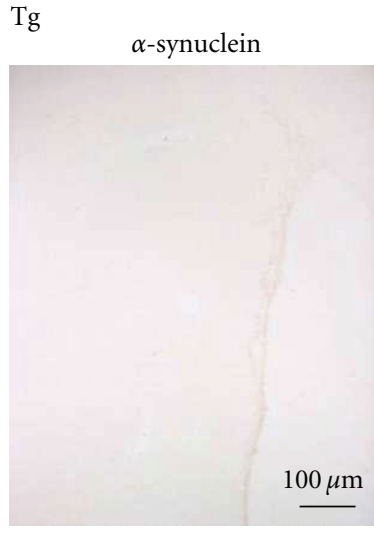

(d)

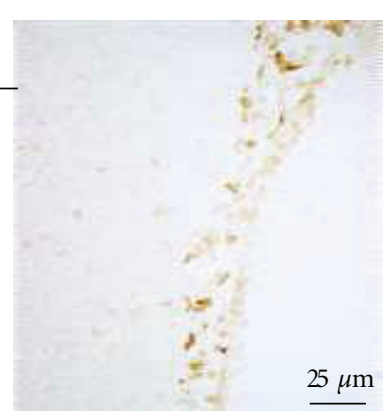

(f)

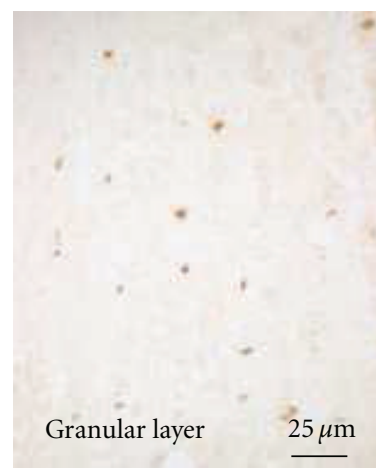

(j)

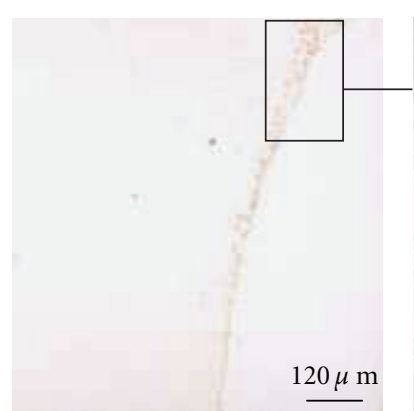

(g)

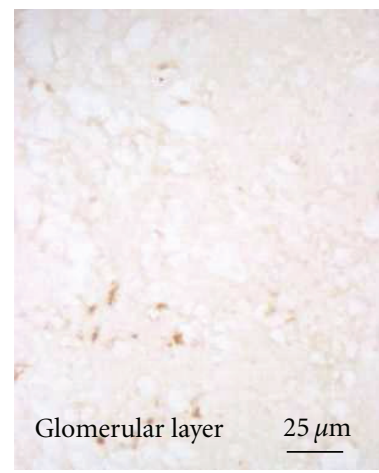

(k)

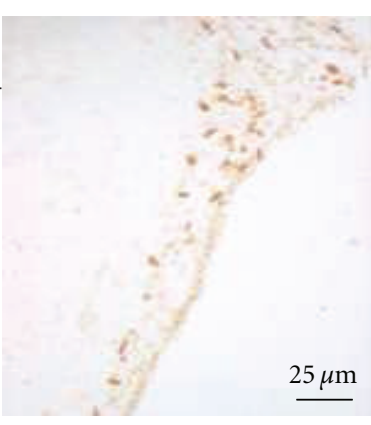

(h)

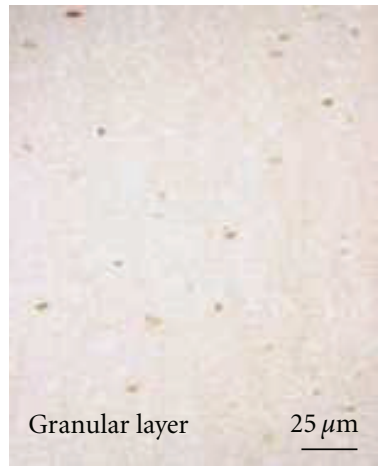

(1)

FIgure 3: Alpha-synuclein, tyrosine hydroxylase (TH), and BrdU immunoreactivity in wild-type (WT) and transgenic (Tg) rats. TH and $\alpha$-syn immunostainings in SVZ in a WT rat $(\mathrm{a}, \mathrm{b})$ and in a transgenic rat $(\mathrm{c}, \mathrm{d})$. BrdU immunostaining in SVZ in a WT rat (e, $\mathrm{f})$ and in a transgenic rat $(\mathrm{g}, \mathrm{h})$. No difference in the number of BrdU positive cells is observed between both groups. F and $\mathrm{H}$ are a higher magnification of E and G, respectively. LV: lateral ventricle; Str: striatum. BrdU immunostaining in glomerular layer (I: WT; K: Tg) and granular cell layer (J: WT; L: Tg) of a section of an olfactory bulb. We can observe an increase of the number of BrdU positive cells in the glomerular layer of transgenic rats as compared to WT animals.

Briefly, after treatment with $\mathrm{H}_{2} \mathrm{O}_{2} 3 \%$ in PBS, sections were incubated overnight in a dilution of primary antibodies. Then, sections were immersed in a 1:500 dilution of secondary biotinylated antibody (Jackson ImmunoResearch Laboratories, West Grove, PA). Then sections were transferred to a Vectastain ABC Kit/PBS for 1 hour (Vector Laboratories, Burkingame, CA); 3,3 diaminobenzidine served as chromogen in the subsequent visualization reaction.

For double immunochemistry labeling and confocal visualization of TH and human $\alpha$-syn, immunofluorescent secondary antibodies were used (anti-mouse IgG alexa568;
Invitrogen, Cergy Pontoise, France and anti-rabbit IgG FITC; JacksonimmunoResearch Laboratories, West Grove, PA).

For BrdU immunohistochemistry, we used a DNA denaturation method consisting in first $30 \mathrm{~min}$ incubation at $37^{\circ} \mathrm{C}$ with $2 \mathrm{~N} \mathrm{HCl}$ in PBS followed by a second incubation in $0.1 \mathrm{M}$ Borax, $\mathrm{pH}: 8.6$ for $30 \mathrm{~min}$.

Thioflavin T (Sigma, St Louis, USA) was used to detect amyloid structure in proteins. Thioflavin $\mathrm{T}$ is a reagent known to become strongly fluorescent upon binding to amyloid fibrils. After 3 washes in PBS, brain sections were immersed in a 1:500 dilution of TO-PRO-3 (Invitrogen, 
Cergy Pontoise, France) to label the cell body in red. Then sections were incubated for 1 hour with thioflavin $\mathrm{T}(0.04 \%)$ in a glycine solution $(50 \mathrm{mM})$.

\subsection{Quantification Procedure}

2.5.1. Proliferative Cells. For BrdU quantification of positive cells within the SVZ, a rectangle $(2500 \times 1000 \mathrm{~mm})$ was drawn around the structure and all stained cells (with a clearly visible positive nucleus) were counted on each section for a total of 10 equally spaced sections from bregma levels 1.70 to $-0.40 \mathrm{~mm}$. The mean of these 10 values (one value per section) was calculated giving one final value per animal.

To get an unbiased estimate of the density of BrdU positive cells within the OB granular and glomerular layers, we used the dissector principle and random systematic sampling [27]. The Mercator stereology analysis software (Explora Nova, La Rochelle, France) was utilized to perform unbiased stereological counts of BrdU positive cell. For the unbiased quantification, a line was drawn around the granular or glomerular layers of each section (12 sections from the 12 different rostrocaudal levels in right and left side of the brain were used). The observer was blinded to the rat group. Cells were counted with a $40 \mathrm{X}$ objective (NA, 0.85) using a Nikon Eclipse E600 microscope (Tokyo, Japan) with a motorized stage $(x, y$, and $z)$. Random and systematic counting frames $(50 \times 50 \mu \mathrm{m}$ squares, regularly spaced by $200 \mu \mathrm{m}$ ) were used [28]. Only BrdU positive cells within the frame were counted on sections (16-um serial sections, one every six sections). A BrdU positive neuron was defined as a clearly visible BrdU-immunoreactive nucleus.

The total number of BrdU positive neurons in both layers was also calculated using the formula $N_{t}=V_{t} / V u \times N u$, where $N_{t}$ is the total number of BrdU positive neurons in the layer, $V_{t}$ is the total volume of the layer, $V u$ is the unit volume in which the number of neurons was counted, and $N u$ is the number of neurons counted in the unit volume. The average of the total amount of cells for each group within the granular and the glomerular layers was then statistically analyzed.

The global volume of the glomerular layer and granular cell layer was estimated without bias (i.e., without systematic error) from the profile areas of the cut sections of the glomerular and granular cell layers. An unbiased estimate of each layer's volume was done using Cavalieri's principle. Accordingly, we multiply the sum of the profile areas of each layer on all sections (regularly spaced) with the distance between the sections [29]. With $V_{t}=$ sum of profile areas $\times$ spacing between sections, spacing between sections $=16 \mu \mathrm{m}$ (sections thickness) $\times 6$ (one every six sections). The average of the total volume for all animals was then calculated.

2.5.2. TH Immunoreactivity in the $O B$. A measure of the width of $\mathrm{TH}$ immunoreactivity within the glomerular layer in the $\mathrm{OB}$ was performed. First, the $\mathrm{OB}$ was divided in 3 equal parts, from the anterior to the posterior axis (giving 3 values: one anterior (at bregma $6.7 \mathrm{~mm}$ ), one medial (at

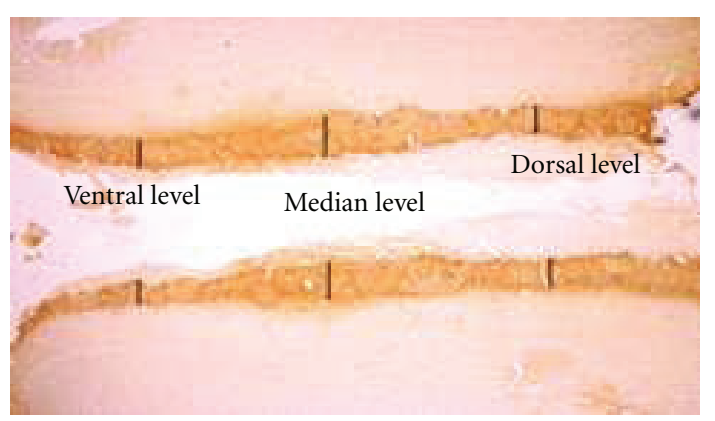

Figure 4: Representation of the 3 dorso-ventral levels used to quantify the width of $\mathrm{TH}$ innervation in the olfactory bulb glomerular layer in wild-type and transgenic rats.

bregma $6.2 \mathrm{~mm}$ ), and one posterior (at bregma $5.7 \mathrm{~mm}$ )), each part containing $4 \mathrm{TH}$-stained sections spaced by 16 microns (for a total of 12 sections for the entire $\mathrm{OB}$ ). Then, for each animal, these 12 coronal sections were visualized using the X4 magnification of an optical microscope (Nikon Eclipse E600, Tokyo, Japan). The width of TH staining corresponding to $\mathrm{TH}$ innervation was measured at 3 dorsoventral levels per section (dorsal, median, and ventral levels; see Figure 4) in both left and right $\mathrm{OB}$ using the ImageJ software (National Institutes of Health, Bethesda, MD). Then the left and right measures from these 3 dorsoventral levels obtained for each section were added together and the mean of the 4 values from each 3 anterior-posterior OB levels was calculated giving one final value per animal for the anterior part of the $\mathrm{OB}$, one final value per animal for the medial part of the $\mathrm{OB}$ and one final value per animal for the posterior part of the OB.

2.5.3. Area of the Glomeruli. A measure of the area of the glomeruli in the $\mathrm{OB}$ was performed on $12 \mathrm{TH}$ stained coronal sections (from bregma $6.7 \mathrm{~mm}$ to $5.7 \mathrm{~mm}$ ) in 3 transgenic and 3 wild-type animals using the ImageJ software (National Institutes of Health, Bethesda, MD). This quantification was performed in order to investigate if a variation in glomeruli area could interact with a difference in glomerular layer $\mathrm{TH}$ innervation pattern between the 2 groups of animals. A total of 45 to 50 areas of glomeruli were measured per animal. Seven area intervals were arbitrary used to rank the glomeruli per size: $0-4330 \mu \mathrm{m}^{2} ; 4331-8660 \mu \mathrm{m}^{2}$; $8661-$ $12990 \mu \mathrm{m}^{2}$; $12991-17320 \mu \mathrm{m}^{2}$; 17321-21650 $\mu \mathrm{m}^{2}$; 21651$25980 \mu \mathrm{m}^{2} ; 25981-30310 \mu \mathrm{m}^{2}$. Data are represented as the percentage of glomeruli for each area interval for each animal.

2.6. Statistical Analysis of the Data. Results from the behavior were expressed as mean \pm SEM and analyzed using an ANOVA and Mann-Whitney. Data from BrdU labeling in the SVZ and in the OB, glomerular TH innervation in the $\mathrm{OB}$ and glomeruli area were expressed as mean \pm SEM. The density and total number of BrdU-positive cells and the width of glomerular TH innervation were then analyzed using the Mann-Whitney statistical test (one-tailed; PRISM; Graph Pad 4.0 software, CA, USA). 


\section{Results}

3.1. Generation of the A30P and A53T $\alpha$-syn Transgenic Rat. Using the transgene construction from Richfield et al. ([14], see Figure 1), 3 lines of transgenic rats expressing both the A30P and A53T mutated forms of the human $\alpha$-syn gene under the control of the TH promoter have been generated. However, only 2 founders were able to transmit the transgene to several generations of offsprings as characterized by PCR (not shown). The MA3 line characterized by 1 or 2 transgene copies was used in our present investigation.

3.2. Investigation of the Olfaction. In the open field, the habituation pattern was identical for both groups of rats (no corner preference). During the olfaction test, WT rats were attracted by the odor of the coconut milk and spent significantly more time in the corner with the coconut milk filter paper as compared to the corner with the distilled water. A ratio of 2 indicates that the rat spent twice as much time visiting the corner with the coconut milk as compared to the corner with the distilled water. On the contrary, transgenic animals significantly spent less time in the corner with the coconut milk as a ratio of 1 corresponds to the same period of time spent in both corners. Therefore, transgenic animals presented olfactory impairments when compared to WT animals (Figure 1(b)). This impairment remained stable from 6 months of age.

No gross alteration in locomotion pattern was observed during the habituation and the olfaction test between both groups of animals.

3.3. Lateral Stepping Test. No significant difference in movement initiation was observed between WT and Tg rats from 14 to 18 months (Figure 1(c)). Results from gross locomotor observations during the investigation of olfaction were confirmed in older rats with the lateral stepping test.

3.4. Immunohistochemistry. Distribution of human $\alpha$-syn protein and DA-labeled cells/processes in the $\mathrm{OB}$ and the SVZ was evaluated by immunohistochemical investigation. All transgenic MA3 brains expressed human $\alpha$-syn protein labeling in the OB (Figure 2(d)). Tyrosine hydroxylase and human $\alpha$-syn immunostainings were only detected in the OB glomerular layer (Figures 2(a), 2(b), 2(c) and 2(d)) of transgenic rats (the same location where the $\mathrm{TH}$ staining was observed in WT animals, Figure 2(a)). Higher magnification using merged fluorescence of TH and $\alpha$-syn stainings showed than most of TH positive neurons in the $\mathrm{OB}$ glomerular layer also expressed the human $\alpha$-syn (Figures 2(e), 2(f), and $2(\mathrm{~d}))$. The confocal analysis confirmed than both human $\alpha$-syn and TH molecules were colocalized in the same cell bodies and processes with a diffuse cellular $\alpha$-syn staining pattern. The cell body contained dense patches positive for human $\alpha$-syn staining and a prominent immunoreactivity in the processes (Figures 2(h), 2(i) and 2(g)). In addition, using the Thioflavin $\mathrm{T}$ staining, numerous aggregates of protein were noticed within the cell body (Figure $2(\mathrm{k})$ ). The antibody used to detect the human $\alpha$-syn was validated by the absence of any human $\alpha$-syn staining in the OB of WT rats (Figure $2(\mathrm{~b})$ ). Neither human $\alpha$-syn positive cells nor TH-labeled cells were visualized within the SVZ from WT or transgenic animals (Figures 3(a), 3(b), 3(c), 3(d)).

BrdU-positive nuclei were observed in the SVZ area in both WT and transgenic rats (Figures 3(e), 3(f), 3(g), and $3(\mathrm{~h}))$. Proliferative-BrdU-labeled cells were also noticed in the OB glomerular (Figures 3(i), 3(k)) and granular cell layers (Figures 3(j), 3(l)). Fewer cells were noted in the WT glomerular layer than in the $\mathrm{Tg}$ glomerular layer.

3.5. Quantification of SVZ Proliferation. We performed counts of BrdU immunoreactive cell bodies to measure the level of SVZ proliferation. No significant difference in BrdU positive cells within the SVZ was noted between the 2 groups of rats (Figures $3(\mathrm{e}), 3(\mathrm{f}), 3(\mathrm{~g}), 3(\mathrm{~h})$, and Table 1 ).

3.6. Quantification of $\mathrm{OB}$ New Generated Cells Within Glomerular and the Granular Cell Layers. Following BrdU injections, proliferation in the $\mathrm{OB}$ was assessed using unbiased stereology. When comparing WT and transgenic rats, no significant difference was observed in the density of resident proliferated cells in the granular cell layer (mean density of BrdU positive cells in transgenic group: $6.32 \times 10^{3}$ versus $5.78 \times 10^{3}$ in the WT group: (Figures $3(\mathrm{j}), 3(\mathrm{l})$, and Table 1 ). In contrast, we observed a statistically significant increase in the density of BrdU positive cells in the glomerular layer of transgenic rats as compared to WT animals $(+68 \%$; $P<$ .05 ; Figures $3(\mathrm{i})$ and $3(\mathrm{k})$ and Table 1$)$. The analysis of the total number of local proliferative cells also showed a significant increase only in the glomerular layer of the transgenic animals as compared to the WT rats (Table 1).

No significant variation in the volume of the glomerular and granular layers was observed between the 2 groups of animals (Table 1).

3.7. Quantification of DA Innervation in Glomerular Layer. To analyze DA innervations in the OB (Figure 4), the width of the TH positive area within the glomerular layer evidenced by $\mathrm{TH}$ immunolabeling was measured at 3 different bregma levels per section (anterior $(6.7 \mathrm{~mm})$, medial $(6.2 \mathrm{~mm})$ and posterior $(5.7 \mathrm{~mm})$ ). An overall $7.9 \%$ increase in the width of $\mathrm{TH}$ innervation was observed in the transgenic rat as compared to WT animals. However, when the OBs were divided along the anterior-posterior axis, only the width calculated at Bregma $6.2 \mathrm{~mm}$ level was significantly increased by $12.4 \%$ in transgenic rat as compared to WT rats $(P<.01$; Table 2).

3.8. Area of the Glomeruli. Glomeruli were distributed from areas inferior to $4330 \mu \mathrm{m}^{2}$ to a maximum area of $30310 \mu \mathrm{m}^{2}$ with most of them having an area comprised between $8660 \mu \mathrm{m}^{2}$ and $12990 \mu \mathrm{m}^{2}$. No significant difference was observed concerning the percentage of glomeruli in each area interval, except for the smaller interval where significantly more transgenic glomeruli $(3.47 \%)$ were contained in the " 0 to $4330 \mu \mathrm{m}^{2}$ " area interval as compared to $1.40 \%$ for the WT glomeruli $(P<.05$; Table 3$)$. 
TABLE 1: Quantification of BrdU positive cells and layer's volume in wild-type and transgenic rats from the olfactory bulb glomerular and granular cell layers and in the SVZ. Mean \pm SEM. ${ }^{*} P<.05$; ns: no statistical difference between the 2 groups. Only the number of BrdU positive cells in the glomerular layer of transgenic rats was significantly increased by $68 \%$ as compared to WT animals. Values are expressed as density per $\mathrm{mm}^{3}$ and total number of BrdU positive neurons.

\begin{tabular}{lccc}
\hline & Wild-type group & Transgenic group & $P<.05$ \\
\hline Glomerular layer density in $\mathrm{mm}^{3}$ & $1.72 \times 10^{3} \pm 0.38 \times 10^{3}$ & $2.90 \times 10^{3} \pm 0.51 \times 10^{3}$ & $*$ \\
Glomerular layer total number & $2.35 \times 10^{3} \pm 0.52 \times 10^{3}$ & $4.13 \times 10^{3} \pm 0.72 \times 10^{3}$ & $*$ \\
Granular cell layer density in $\mathrm{mm}^{3}$ & $5.78 \times 10^{3} \pm 0.79 \times 10^{3}$ & $6.32 \times 10^{3} \pm 1.14 \times 10^{3}$ & $\mathrm{~ns}$ \\
Granular cell layer total number & $16.6 \times 10^{3} \pm 2.28 \times 10^{3}$ & $19.27 \times 10^{3} \pm 3.48 \times 10^{3}$ & $\mathrm{~ns}$ \\
Subventricular zone total number & $85.1 \times 10^{3} \pm 21.4 \times 10^{3}$ & $121 \times 10^{3} \pm 16.1 \times 10^{3}$ & $\mathrm{~ns}$ \\
Glomerular layer volume in $\mathrm{mm}^{3}$ & $1.364 \pm 0.21$ & $1.423 \pm 0.06$ & $\mathrm{~ns}$ \\
Granular layer volume in $\mathrm{mm}^{3}$ & $2.872 \pm 0.41$ & $3.050 \pm 0.202$ & $\mathrm{~ns}$ \\
\hline
\end{tabular}

TABLE 2: Measure of the width of TH innervation in the olfactory bulb glomerular layer in wild-type and transgenic rats. The width was measured in the anterior level (bregma $6.7 \mathrm{~mm}$ ), in the median level (bregma $6.2 \mathrm{~mm}$ ), and in the posterior level (bregma $5.7 \mathrm{~mm}$ ) of the olfactory bulb. Mean \pm SEM. ${ }^{* *} P<.01$; ns: no statistical difference between the 2 groups. A significant increase of the TH innervation was observed for bregma $6.2 \mathrm{~mm}$ level in transgenic as compared to wild type rats.

\begin{tabular}{lccl}
\hline & Wild-type group & Transgenic group & $P<.01$ \\
\hline Bregma: $6.7 \mathrm{~mm}$ & $434.2 \pm 16.46$ & $480.9 \pm 34.23$ & $\mathrm{~ns}$ \\
Bregma: $6.2 \mathrm{~mm}$ & $572.5 \pm 17.63$ & $643.6 \pm 8.18$ & $* *$ \\
Bregma: $5.7 \mathrm{~mm}$ & $684.4 \pm 51.34$ & $701.0 \pm 48.79$ & $\mathrm{~ns}$ \\
\hline
\end{tabular}

\section{Discussion}

Our study used the first $\alpha$-syn transgenic rat bearing the human A30P and A53T mutations under the control of the TH promoter. As previously stated $[19,20]$ transgenic animals displayed some long-lasting olfactory deficits and the human-mutated $\alpha$-syn protein was observed in the $\mathrm{OB}$, the SNpc, and the LC. It was colocalized with $\mathrm{TH}$ immunostaining (as shown for the $\mathrm{OB}$ in the present paper) which is consistent with the fact that $\mathrm{TH}$ was the transgene promoter. Olfactory deficits appeared long before the motor alterations as 18-month old animal did not present yet any deficit in movement initiation. Deficits in motor coordination appeared at 19 months of age (not shown). Twenty-fivemonth-old transgenic rats were used in this study as clinical and pathological manifestations of the $\alpha$-syn mutations appear in advanced age in PD, generally [22]. Tyrosine hydroxylase was used as the promoter in order to obtain the human $\alpha$-syn synthesis only in catecholaminergic structures. Indeed, we were able to observe transgene expression in the 3 main catecholaminergic brain areas involved in the course of PD: the $\mathrm{OB}$, the SNpc, and the locus coeruleus. To date, there is a growing evidence of a prion-like transmission of $\alpha$ syn contained in aggregates from donor cell to recipient cell [30]. However, it did not seem to be the case in our transgenic rat as non-TH positive brain structures did not contain any human $\alpha$-syn molecule. However, we cannot rule out that this mechanism did not happen within catecholaminergic structures, thus potentiating the effect of the transgene.

The $\mathrm{OB}$ is a brain region of particular interest because Lewy neurites and bodies are present in this area in the very early stages of the PD [31]. These inclusions consist of aggregated form of $\alpha$-syn with other components such as phosphorylated neurofilaments and ubiquitin [31]. As in PD patients, we have shown that our mutant human A53T and A30P $\alpha$-syn expressing rat presented protein aggregates in the glomerular layer suggesting an implication of the humanmutated $\alpha$-syn in the cellular processing of aggregates, which could in turn alter local OB proliferation.

Our data showed an increased number of proliferative cells in the glomerular layer but not in the granular cell layer. It is worth mentioning here that the BrdU protocol used in the present study rather revealed local OB proliferation than migrated cells from the SVZ to the $\mathrm{OB}$ as the animals were given BrdU for 5 days and sacrificed 5 hours after the last injection.

Interestingly, Winner et al. [32] showed in 2-month-old female Wistar rats that the local dividing cells represented less than $5 \%$ of the total number of new cells. Their total number of BrdU positive cells in the granular (8,200 cells) and glomerular layer (250) are lower than ours (16,600 cells and 2,350 cells, resp.). This important difference in numbers can be related to the concentration of BrdU used in Winner's study being half of the one we used, to the time of the sacrifice after the last injection ( $2 \mathrm{~h}$ versus $5 \mathrm{~h}$ in our study), to the age of the animal ( 2 months versus 25 months) and could point out for a few cells an increase in granular and glomerular layer local proliferation due to aging.

No variation in the SVZ proliferation was induced by the double $\alpha$-syn mutation. This later result can be explained by the absence of any transgene expression within the SVZ. Our observation in the SVZ is in agreement with the findings of Maxreiter et al. [21] using a mouse expressing the human A30P mutant form of the $\alpha$-syn, who did not find any change in SVZ proliferation. Using mice expressing the A30P mutant form of $\alpha$-syn under the control of the calcium/calmodulindependent protein kinase II alpha (CaMK) promoter [21] 
TABLE 3: Distribution of glomeruli (in \%) by area from TH-stained sections in wild-type and transgenic groups. Seven intervals of area were used: $0-4330 \mu \mathrm{m}^{2} ; 4330-8660 \mu \mathrm{m}^{2} ; 8660-12990 \mu \mathrm{m}^{2} ; 12990-17320 \mu \mathrm{m}^{2} ; 17320-21650 \mu \mathrm{m}^{2} ; 21650-25980 \mu \mathrm{m}^{2} ; 25980-30310 \mu \mathrm{m}^{2}$. Mean \pm SEM. ${ }^{*} P<.05$; ns: no statistical difference between the 2 groups. There is no significant difference between both groups except for the smaller interval.

\begin{tabular}{lccc}
\hline Interval & Wild-type group & Transgenic group & $P<.05$ \\
\hline $0-4330 \mu \mathrm{m}^{2}$ & $1.403 \pm 0.701$ & $3.471 \pm 0.486$ & $*$ \\
$4331-8660 \mu \mathrm{m}^{2}$ & $17.06 \pm 3.556$ & $19.11 \pm 1.780$ & $\mathrm{~ns}$ \\
$8661-12990 \mu \mathrm{m}^{2}$ & $37.67 \pm 3.353$ & $31.26 \pm 0.077$ & $\mathrm{~ns}$ \\
$12991-17320 \mu \mathrm{m}^{2}$ & $31.72 \pm 4.339$ & $22.56 \pm 3.162$ & $\mathrm{~ns}$ \\
$17321-21650 \mu \mathrm{m}^{2}$ & $7.423 \pm 2.246$ & $17.63 \pm 3.261$ & $\mathrm{~ns}$ \\
$21651-25980 \mu \mathrm{m}^{2}$ & $3.405 \pm 0.642$ & $3.217 \pm 1.725$ & $\mathrm{~ns}$ \\
$25981-30310 \mu \mathrm{m}^{2}$ & $1.307 \pm 1.307$ & $2.731 \pm 0.254$ & $\mathrm{~ns}$ \\
\hline
\end{tabular}

or expressing the A53T mutant form of $\alpha$-syn under the control of the PDGF-promoter [22], two groups studying OB neurogenesis found a decrease in newly generated neurons in the glomerular and granular layers. Taken together, the data on $\mathrm{OB}$ neurogenesis and from our own investigation suggest that human $\alpha$-syn A30P/A53T mutations impacts newly generated neuroblasts during $\mathrm{OB}$ integration/differentiation as well as local $O B$ proliferation. In contrast to our observations and certainly due to the promoter they used, Winner et al. [22] and Maxreiter et al. [21] also observed some transgene expression in noncatecholaminergic structures. Some data suggest that the mutated $\alpha$-syn could spread using a prionlike transmission from cell to cell [30]. As a result, it is possible that a more " $\alpha$-syn toxic brain environment" was created in the A30P and the A53T transgenic mouse brains than in our rat brain. The increased local proliferation that we noticed in the glomerular layer is in agreement with data from the glomerular layer of PD patients [23]. This later finding suggests that our rat model is a suitable tool concerning the effects of the $\alpha$-syn mutations in the OB.

As proliferative cells within the glomerular layer are known to differentiate in DA neurons [24], we investigated the TH innervation within the glomerular layer. We observed an increase in width of the TH positive area in the glomerular layer without an increase in the size of the glomeruli (except for the smaller interval in transgenic animals) suggesting that this increased TH innervation was not induced by an increased glomerular layer areas (as an increased glomeruli size would have increased the size of the glomerular layer which in turn could have enlarged the pattern of $\mathrm{TH}$ innervation). This result is agreement with the $100 \%$ increase in DA cell number in the glomerular layer from PD patients [23]. Although the mechanisms underlying the enhanced $\mathrm{DA}$ innervation in the $\mathrm{OB}$ glomerular layer remains to be determined, various growth factors which play an important role in $\mathrm{OB}$ proliferation and DA differentiation could be involved such as BDNF, GDNF and CNTF [33]. Interestingly, this increase in DA innervation observed in our transgenic rat and in PD patients could explain, at least in part, the olfactory deficit observed both in our rat and in patients as DA in the OB has an inhibitory action. Hyposmia can be detected in PD patients in early stage of disease. Our transgenic rats have been tested for olfactory function at different ages (from one week to 25 months of age) and at
6 months of age they presented an alteration of olfaction. Dopamine has an important role in mediating olfactory information into the brain [34]. TH innervation is found exclusively in glomerular layer of the $\mathrm{OB}$ [25]. In our rat, the increase in TH innervation in this area might suggest an increase in DA release. DA is known to induce an inhibition between olfactory receptor cells and mitral cells within glomerular layer [23]. D2 receptors are the most abundant subtype of DA receptors in the glomerular layer [35] and are involved in the decrease in synaptic transmission [34]. The increase of DA neurons caused by the A30P and the A53T mutant forms of $\alpha$-syn could induce a depression in synaptic transmission and therefore compromises the threshold for olfaction. This circuit is the first step in the process of final consciousness of smell and therefore is essential for the proper function of olfactory circuits. Data from biopsies of patients diagnosed with PD support the idea that olfactory impairment in PD do not result from damage to the olfactory epithelium but is the consequence of central-nervous alterations [36]. Thus our rat could be a good model to investigate the role of human mutated $\alpha$-syn in the development of olfactory deficits.

In conclusion, we generated a human double mutated $\alpha$ syn (A30P and A53T) transgenic rat presenting an alteration of the local proliferation in the glomerular layer but neither in the granular cell layer of the OB nor in the SVZ. In addition, an increase in DA glomerular layer innervation was noticed, which might be related to the increased proliferation observed in this layer. Further investigation should examine the time course of the changes in the olfactory function in regards to alterations in OB local proliferation as well as elucidate the role of the increased DA function in the olfactory deficits we observed in our transgenic rat.

\section{Acknowledgments}

The authors wish to thank Pr. H. J. Federoff, University of Rochester, New York, for the gift of the transgene construct, P. Hulin, Ph.D., from the University of Nantes IFR26 "Plate-forme MicroPICell" for the use of the confocal microscope, V. Paillé, Ph.D. for stimulating discussion on unbiased stereological procedures, and K. D. Fink, MS for proof reading. This study was supported by the Fondation 
de France (PD), France Parkinson (PD), CECAP (CB), INSERM-Région des Pays de la Loire (FL) and Progreffe foundation (INSERM UMR 643). F. Lelan, C. Boyer, P. Naveilhan, and L. Lescaudron are contributed equally to this work.

\section{References}

[1] D. Lee, S. Lee, E. Lee, C. Chang, and S. R. Paik, "Alphasynuclein exhibits competitive interaction between calmodulin and synthetic membranes," Journal of Neurochemistry, vol. 82, no. 5, pp. 1007-1017, 2002.

[2] P. T. Kotzbauer, B. I. Giasson, A. V. Kravitz et al., "Fibrillization of [alpha]-synuclein and tau in familial Parkinson's disease caused by the A53T [alpha]-synuclein mutation," Experimental Neurology, vol. 187, no. 2, pp. 279-288, 2004.

[3] A. H. V. Schapira, "Etiology of Parkinson's disease," Neurology, vol. 66, no. 10, supplement 4, pp. S10-S23, 2006.

[4] R. Kruger, W. Kuhn, T. Muller et al., "AlaSOPro mutation in the gene encoding [alpha]-synuclein in Parkinson's disease," Nature Genetics, vol. 18, no. 3, pp. 106-108, 1998.

[5] M. H. Polymeropoulos, J. J. Higgins, L. I. Golbe et al., "Mapping of a gene for Parkinson's disease to chromosome 4q21-q23," Science, vol. 274, no. 5290, pp. 1197-1199, 1996.

[6] M. H. Polymeropoulos, C. Lavedan, E. Leroy et al., "Mutation in the $\alpha$-synuclein gene identified in families with Parkinson's disease," Science, vol. 276, no. 5321, pp. 2045-2047, 1997.

[7] J. J. Zarranz, J. Alegre, J. C. Gómez-Esteban et al., “The new mutation, E46K, of $\alpha$-synuclein causes Parkinson and Lewy body dementia," Annals of Neurology, vol. 55, no. 2, pp. 164173,2004 .

[8] M. G. Spillantini, M. L. Schmidt, V. M. Lee, J. Q. Trojanowski, R. Jakes, and M. Goedert, "[alpha]-synuclein in Lewy bodies ," Nature, vol. 388, no. 6645, pp. 839-840, 1997.

[9] P. J. Kahle, M. Neumann, L. Ozmen, and C. Haass, "Physiology and pathophysiology of alpha-synuclein cell culture and transgenic animal models based on a Parkinson's disease-associated protein," Annals of the New York Academy of Sciences, vol. 920, pp. 33-41, 2000.

[10] E. Rockenstein, M. Mallory, M. Hashimoto et al., "Differential neuropathological alterations in transgenic mice expressing alpha-synuclein from the platelet-derived growth factor and Thy-1 promoters," Journal of Neuroscience Research, vol. 68, no. 5, pp. 568-578, 2002.

[11] S. Gispert, D. D. Turco, L. Garrett et al., "Transgenic mice expressing mutant A53T human alpha-synuclein show neuronal dysfunction in the absence of aggregate formation," Molecular and Cellular Neuroscience, vol. 24, no. 2, pp. 419429, 2003.

[12] H. Van Der Putten, K. Wiederhold, A. Probst et al., "Neuropathology in mice expressing human alpha-synuclein," Journal of Neuroscience, vol. 20, no. 16, pp. 6021-6029, 2000.

[13] B. I. Giasson, J. E. Duda, S. M. Quinn, B. Zhang, J. Q. Trojanowski, and V. M. Lee, "Neuronal [alpha]-synucleinopathy with severe movement disorder in mice expressing A53T human [alpha]-synuclein," Neuron, vol. 34, no. 4, pp. 521-533, 2002.

[14] E. K. Richfield, M. J. Thiruchelvam, D. A. Cory-Slechta et al., "Behavioral and neurochemical effects of wild-type and mutated human alpha-synuclein in transgenic mice," Experimental Neurology, vol. 175, no. 1, pp. 35-48, 2002.

[15] T. Gomez-Isla, M. C. Irizarry, A. Mariash et al., "Motor dysfunction and gliosis with preserved dopaminergic markers in human [alpha]-synuclein A30P transgenic mice," Neurobiology of Aging, vol. 24, no. 2, pp. 245-258, 2003.

[16] C. Lo Bianco, J. L. Ridet, B. L. Schneider, N. Déglon, and P. Aebischer, "Alpha-synucleinopathy and selective dopaminergic neuron loss in a rat lentiviral-based model of Parkinson's disease," Proceedings of the National Academy of Sciences of the United States of America, vol. 99, no. 16, pp. 10813-10818, 2002.

[17] M. Yamada, T. Iwatsubo, Y. Mizuno, and H. Mochizuki, "Overexpression of alpha-synuclein in rat substantia nigra results in loss of dopaminergic neurons, phosphorylation of alpha-synuclein and activation of caspase-9: resemblance to pathogenetic changes in Parkinson's disease," Journal of Neurochemistry, vol. 91, no. 2, pp. 451-461, 2004.

[18] D. Kirik, C. Rosenblad, C. Burger et al., "Parkinson-like neurodegeneration induced by targeted overexpression of $\alpha$ synuclein in the nigrostriatal system," Journal of Neuroscience, vol. 22, no. 7, pp. 2780-2791, 2002.

[19] C. Boyer, R Thinard, S Rémy et al., The Alpha-Synuclein Rat: A New Transgenic Model of Presymptomatic Parkinson's Disease, Society for Neuroscience Meeting, Wash, USA.

[20] C. Boyer, F. Lelan, R. Thinard et al., "A new model of presymptomatic Parkinson's disease: the alpha-synuclein rat bearing the A30P and A53T mutations," submitted.

[21] F. Marxreiter, S. Nuber, M. Kandasamy et al., "Changes in adult olfactory bulb neurogenesis in mice expressing the A30P mutant form of alpha-synuclein," European Journal of Neuroscience, vol. 29, no. 5, pp. 879-890, 2009.

[22] B. Winner, E. Rockenstein, D. C. Lie et al., "Mutant alphasynuclein exacerbates age-related decrease of neurogenesis," Neurobiology of Aging, vol. 29, no. 6, pp. 913-925, 2008.

[23] E. Huisman, H. B. Uylings, and P. V. Hoogland, "A 100\% increase of dopaminergic cells in the olfactory bulb may explain hyposmia in parkinson's disease," Movement Disorders, vol. 19, no. 6, pp. 687-692, 2004.

[24] C. Lois and A. Alvarez-Buylla, "Long-distance neuronal migration in the adult mammalian " Brain Science, vol. 264, no. 5162, pp. 1145-1148, 1994.

[25] N. Hala'sz, A. Ljungdahl, T. Hökfelt et al., “Transmitter histochemistry of the rat olfactory bulb. I. immunohistochemical localization of monoamine synthesizing enzymes. Support for intrabulbar, periglomerular dopamine neurons," Brain Research, vol. 126, no. 3, pp. 455-474, 1977.

[26] M. Lemasson, C. Delbé, G. Gheusi, J. D. Vincent, and P. M. Lledo, "Use of ultrasonic vocalizations to assess olfactory detection in mouse pups treated with 3-methylindole," Behavioural Processes, vol. 68, no. 1, pp. 13-23, 2005.

[27] R. E. Coggeshall, "A consideration of neural counting methods," Trends Neurosci, vol. 15, no. 1, pp. 9-13, 1992.

[28] V. Ghiglieri, B. Picconi, C. Sgobio et al., "Epilepsy-induced abnormal striatal plasticity in Bassoon mutant mice," European Journal of Neuroscience, vol. 29, no. 10, pp. 1979-1993, 2009.

[29] C. Schmitz and P. R. Hof, "Design-based stereology in neuroscience," Neuroscience, vol. 130, no. 4, pp. 813-831, 2005.

[30] E. Angot and P. Brundin, "Dissecting the potential molecular mechanisms underlying [alpha]-synuclein cell-to-cell transfer in Parkinson's disease," Parkinsonism and Related Disorders, vol. 15, supplement 3, pp. S143-S147, 2009.

[31] H. Braak, K. D. Tredici, U. Rüb, R. A. I. De Vos, E. N. H. Jansen Steur, and E. Braak, "Staging of brain pathology related to sporadic Parkinson's disease," Neurobiology of Aging, vol. 24, no. 2, pp. 197-211, 2003. 
[32] B. Winner, C. M. Cooper-Kuhn, R. Aigner, J. Winkler, and H. G. Kuhn, "Long-term survival and cell death of newly generated neurons in the adult rat olfactory bulb," European Journal of Neuroscience, vol. 16, no. 9, pp. 1681-1689, 2002.

[33] M. E. Buckland and A. M. Cunningham, "Alterations in the neurotrophic factors BDNF, GDNP and CNTF in the regenerating olfactory system," Annals of the New York Academy of Sciences, vol. 855, pp. 260-265, 1998.

[34] A. Y. Hsia, J. Vincent, and P. Lledo, "Dopamine depresses synaptic inputs into the olfactory bulb," Journal of Neurophysiology, vol. 82, no. 2, pp. 1082-1085, 1999.

[35] V. Coronas, L. K. Srivastava, J. J. Liang, F. Jourdan, and E. Moyse, "Identification and localization of dopamine receptor subtypes in rat olfactory mucosa and bulb: a combined in situ hybridization and ligand binding radioautographic approach," Journal of Chemical Neuroanatomy, vol. 12, no. 4, pp. 243-257, 1997.

[36] M. Witt, K. Bormann, V. Gudziol et al., "Biopsies of olfactory epithelium in patients with Parkinson's disease," Movement Disorders, vol. 24, no. 6, pp. 906-914, 2009. 


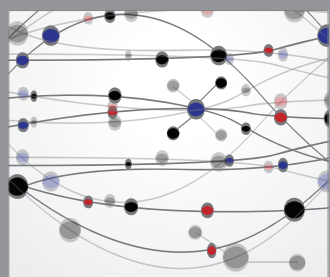

The Scientific World Journal
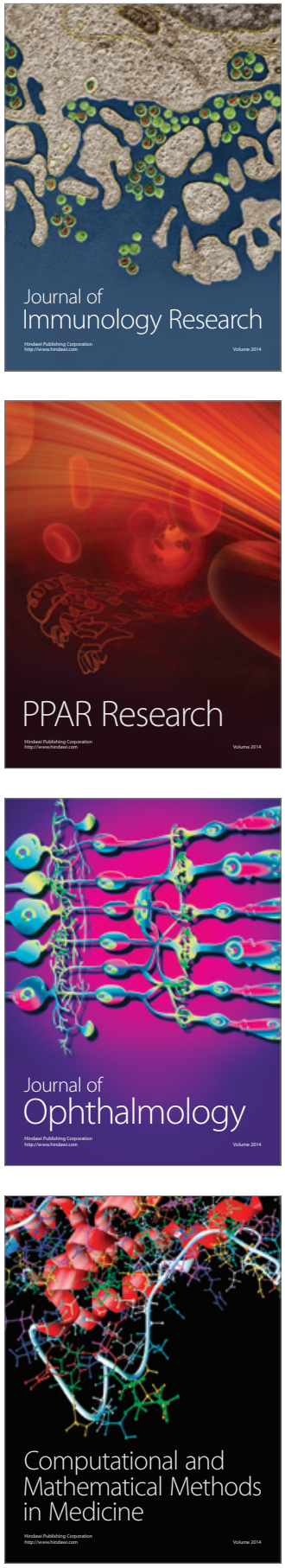

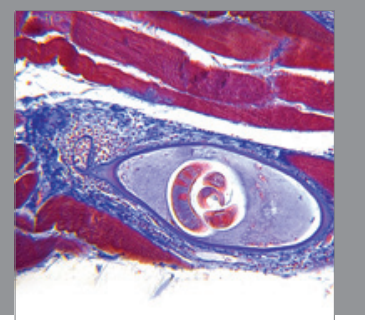

Gastroenterology

Research and Practice
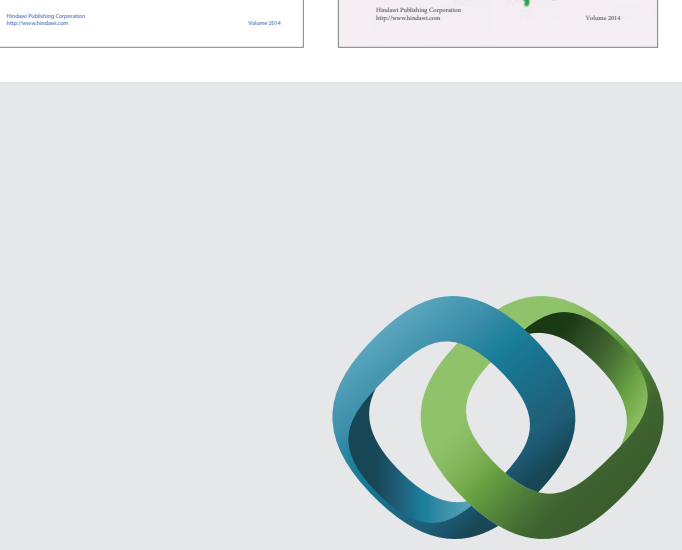

\section{Hindawi}

Submit your manuscripts at

http://www.hindawi.com
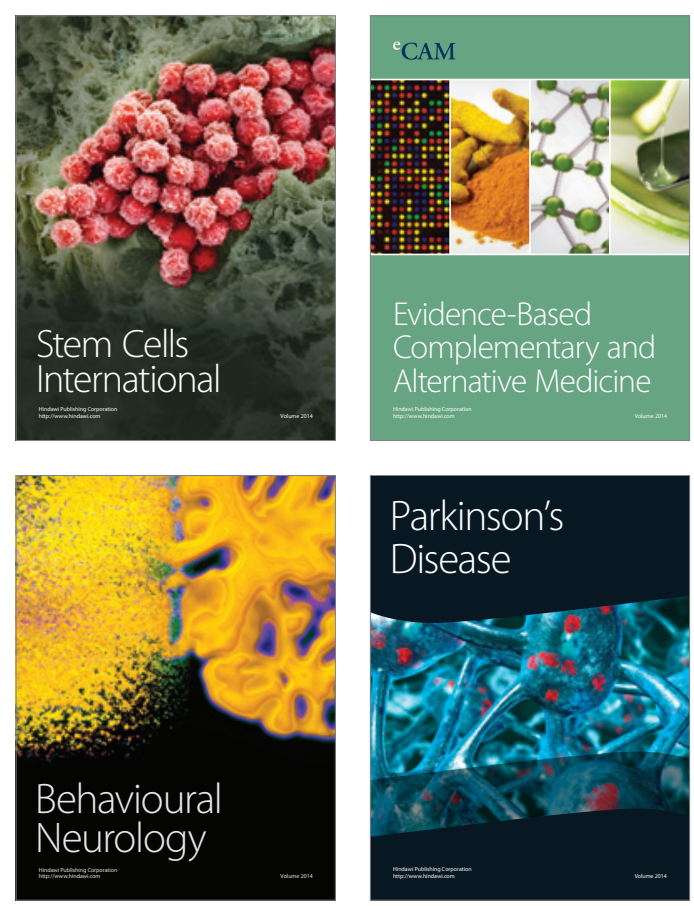

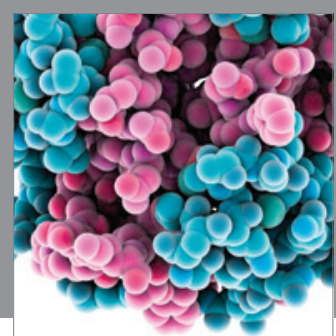

Journal of
Diabetes Research

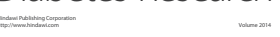

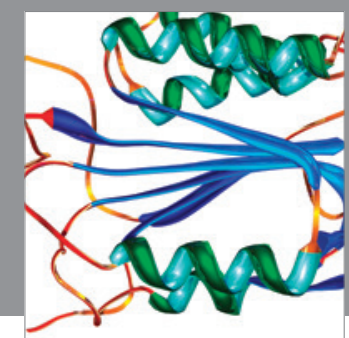

Disease Markers
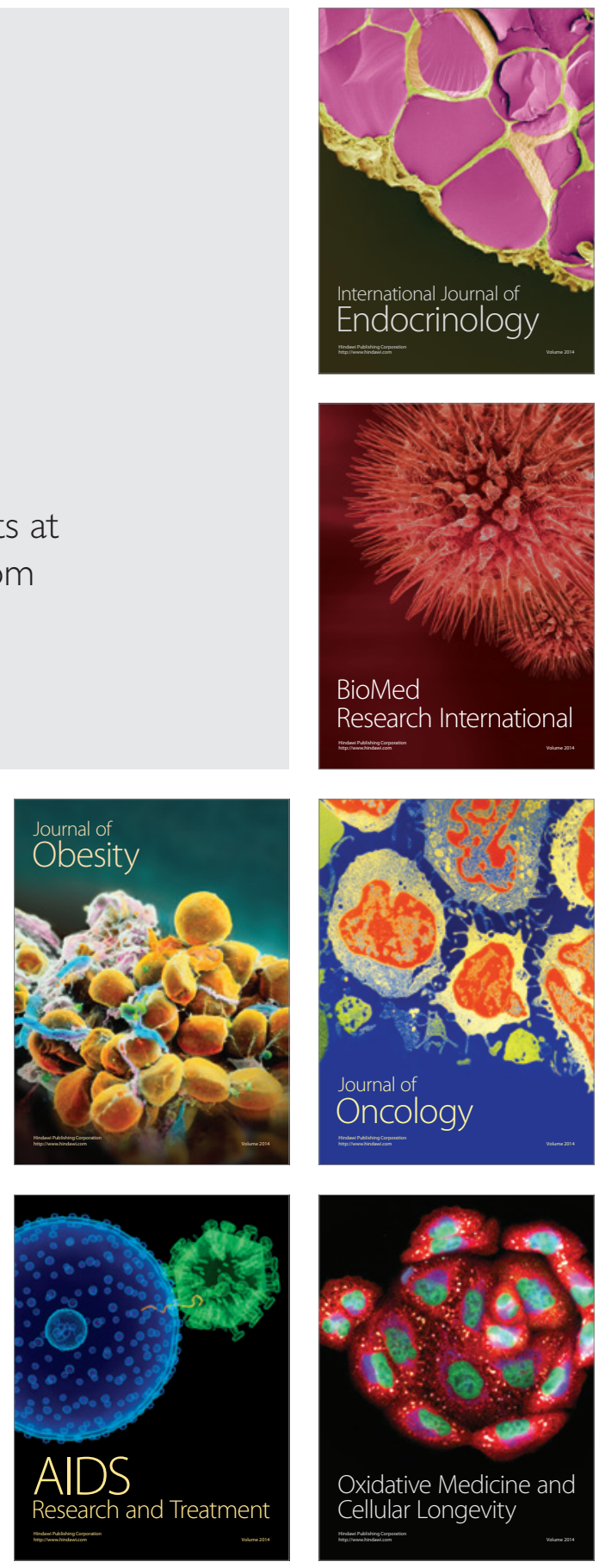